\title{
Sodium glycerophosphate and prescribed calcium concentrations in pediatric parenteral nutrition: a retrospective observational study and economic evaluation
}

Tippawan Siritientong ${ }^{1, *}$, Suree Nimitwongsin ${ }^{2}$

\begin{abstract}
Background: The risk of precipitation limits calcium and phosphate concentrations that can be administered parenterally to pediatric patients. As an alternative to dipotassium phosphate, sodium glycerophosphate (NaGlyP) is claimed to reduce the risk of precipitation in solutions for parenteral administration.

Objectives: To determine the calcium concentrations, NaGlyP, and dipotassium phosphate prescribed in pediatric parenteral nutrition orders and the cost-benefit of the organic phosphate.

Methods: We retrospectively collected cross-sectional data for parenteral nutrition orders from September 2014 to August 2015 for pediatric patients including neonates and children aged $<18$ years who were admitted to King Chulalongkorn Memorial Hospital, Bangkok, Thailand. Calcium concentration, calcium concentration adjustments, and costs of phosphate used per bag were analyzed.

Results: Of 2,192 parenteral nutrition orders, NaGlyP was used in 2,128 (97.1\%) with calcium concentrations in the range of $0.84-139.91 \mathrm{mmol} / \mathrm{L}$, which were significantly higher than calcium concentrations used with dipotassium phosphate $(0.00-12.21 \mathrm{mmol} / \mathrm{L}, P<0.001)$. There was no report of visible precipitation. Median costs of NaGlyP and dipotassium phosphate used per unit bag were not significantly different (35.88 and 41.25 Thai baht [THB] or 1.04 and 1.20 USD per bag, respectively, $P>0.99$; (1 USD equivalent to 34.241 THB U.S. Federal Reserve Bank G5.A annual average rate 2015). Conclusions: Higher calcium concentrations could be achieved without increasing the direct cost per unit bag significantly as a result of using NaGlyP, an alternative to dipotassium phosphate as a source of phosphate for patients who require high amounts of calcium in parenteral nutrition.
\end{abstract}

Keywords: alpha-glycerophosphoric acid; glycerophosphates; calcium; chemical precipitation; parenteral nutrition; phosphates

Calcium and phosphorus requirements of pediatric patients, especially for preterm infants, are high because of the increased need to avoid metabolic bone disease and increase bone mineralization in these patients [1-3]. Incompatibly high concentrations of calcium and phosphates in the pediatric parenteral nutrition preparations may form insoluble dibasic

*Correspondence to: Tippawan Siritientong, Department of Food and Pharmaceutical Chemistry, Faculty of Pharmaceutical Sciences, Chulalongkorn University, Bangkok 10330, Thailand, e-mail: tippawan.s@pharm.chula.ac.th 'Department of Food and Pharmaceutical Chemistry, Faculty of Pharmaceutical Sciences, Chulalongkorn University, Bangkok 10330, Thailand 2Department of Pharmacy, King Chulalongkorn Memorial Hospital, Bangkok 10330, Thailand

Ә Open Access. $\odot 2018$ Siritientong and Nimitwongsin, published by Sciendo. (cc) BY-NC-ND This work is licensed under the Creative Commons Attribution NonCommercial-NoDerivatives 4.0 License. 
calcium-phosphate precipitates, which can cause microvascular pulmonary emboli, respiratory distress, and even death [4]. Separating the administration of calcium and phosphates is one way of achieving the high requirements of pediatric patients and avoiding precipitates, but reduces the benefits for bone mineralization and inevitably induces mineral imbalances [5]. Decreasing the administered calcium and phosphate concentrations according to published compatibility curves, limits the amount of calcium and phosphate that are given to pediatric patients [6]. Therefore, it remains a challenge to meet the calcium and phosphate requirements of patients without complications from calcium phosphate precipitation.

The current practice to avoid calcium-phosphate precipitation in compounding parenteral nutrition solutions is to plot the calcium and phosphate concentrations from a set of published graphs that is the model of the solution composition to make the best judgment of physical stability [4, 6-8]. However, this step may be inconvenient for parenteral nutrition prescription and compounding. Organic phosphates have advantages over inorganic phosphates in the stability of parenteral nutrition solutions. Organic phosphates in concentrations ranging from 0 to $50 \mathrm{mmol} / \mathrm{L}$ showed no precipitation with calcium concentrations up to $50 \mathrm{mEq} / \mathrm{L}$, while conventional inorganic phosphates produced precipitates immediately, on mixing, or during storage $[6,9]$. No precipitation was found with sodium glycerophosphate (NaGlyP) $50 \mathrm{mmol} / \mathrm{L}$ and calcium gluconate $30 \mathrm{mmol} / \mathrm{L}$ [10]. Ronchera-Oms et al. [11] investigated the stability of parenteral nutrition solutions containing $0.5 \%$ amino acids and calcium chloride $4.50 \mathrm{mmol} / \mathrm{L}$ mixed with the organic phosphate, NaGlyP $10.47 \mathrm{mmol} / \mathrm{L}$, or inorganic phosphate $10 \mathrm{mmol} / \mathrm{L}$ at $5{ }^{\circ} \mathrm{C}$ and $22^{\circ} \mathrm{C}$ for up to 72 h. Parenteral nutrition solutions containing NaGlyP were all physically stable when inorganic phosphate salts produced precipitates. de Oliveira Ribeiro et al. [12] investigated the stability of parenteral nutrition solutions containing $1.0 \%$ amino acids, calcium gluconate $0,11.63$, and $23.25 \mathrm{mmol} / \mathrm{L}$, and $\mathrm{NaGlyP} 3.67 \mathrm{mmol} / \mathrm{L}$ at $4^{\circ} \mathrm{C}, 25^{\circ} \mathrm{C}$, and $37^{\circ} \mathrm{C}$ for 7 days. None of them showed any precipitation. Thowladda and Siritientong [13] also reported high compatible concentrations of calcium and phosphate in parenteral nutrition solutions when mixed calcium gluconate together with NaGlyP in vitro. Organic phosphates considerably increase the calcium and phosphate compatibility in parenteral nutrition admixtures, compared with inorganic salts.

NaGlyP, which is available in Thailand, may be an alternative source of organic phosphorous in pediatric parenteral solutions and can be used to avoid calcium-phosphate precipitation $[3,14]$. However, NaGlyP is more expensive than inorganic salts, is not included in the Thai National Formulary, and has no established compatibility curve. Pediatricians may be reluctant to order NaGlyP, and it may be unaffordable for some patients. The use of NaGlyP with calcium gluconate in a clinical setting is rarely reported [3, 6-8, 14, 15]. Although mentioned by Pereira-da-Silva et al. [3], to our knowledge, no studies have investigated the differential cost of its use. Our objective was to determine calcium concentrations prescribed in pediatric parenteral nutrition orders, the corresponding NaGlyP concentrations compared with inorganic dipotassium phosphate salt, and to determine their relative costs in a large public general and tertiary referral teaching hospital in Thailand. This aim was to provide evidence-based data for pediatricians who need to prescribe an intravenous phosphate product with high concentrations of calcium in parenteral nutrition in public health settings in Asia.

\section{Materials and methods}

The study protocol was approved by the Institutional Review Board of the Faculty of Medicine, Chulalongkorn University, Thailand (certicate of approval no. 797/2015) following the principles of the Declaration of Helsinki and its contemporary amendments. This retrospective cross-sectional study reviewed the parenteral nutrition orders from September 2014 to August 2015 for pediatric patients including neonates and children aged $<18$ years who were admitted to King Chulalongkorn Memorial Hospital, Bangkok, Thailand, a public general and tertiary referral teaching hospital with approximately 1,500 beds. A requirement for informed consent was waived due to the retrospective nature of the study and anonymous nature of the data reported. Exclusion criteria included orders without a phosphate concentration or with an unspecified route of administration. Unclear handwritten orders were also excluded. Demographic data of the pediatric patients who required parenteral nutrition including age, sex, medical conditions, and nutritional assessment according to the opinion of the pediatricians were recorded. Route of administration and intravenous calcium and phosphate concentrations were the main outcomes to analyze the effect of NaGlyP, dipotassium phosphate, or mixed phosphate salts in a parenteral nutrition bag, on calcium concentrations. Calcium gluconate was the source of calcium in all parenteral nutrition solutions. Other factors that could be involved in calcium-phosphate precipitation including concentrations of amino acids, sodium, potassium, magnesium, and trace elements were also recorded. Trace elements refer to minerals in Peditrace (Fresenius Kabi, Austria), a commercial product used at King Chulalongkorn Memorial Hospital. The direct costs of the phosphates used in pediatric parenteral nutrition were calculated according to the prices of NaGlyP (Fresenius Kabi) and dipotassium phosphate 
(Thai Otsuka Pharmaceutical Co.) provided at the Department of Pharmacy, King Chulalongkorn Memorial Hospital.

Data were analyzed using IBM SPSS Statistics for Windows (version 22.0) with a defined level of significance at $P<0.05$ for tests of statistical inference. Demographic data are shown as frequencies and percentages. A KolmogorovSmirnov test was used to determine the normality of data. There were 3 independent groups for analysis according to the phosphate salts used: NaGlyP or dipotassium phosphate or mixed phosphate salts. A one-way analysis of variance (ANOVA) was used to compare the means of data with normal distribution, and a Kruskal-Wallis test was used for nonparametric data.

\section{Results}

We examined 3,535 parenteral nutrition orders made from September 2014 to August 2015; 2,192 of these orders were included in the present study. Demographic data of pediatric patients recorded in parenteral nutrition orders are summarized in Table 1. Most patients were aged $\leq 1$ year $(84.8 \%)$, of whom, about half were mildly malnourished (55.3\%) with complex medical conditions (50\%).

Table 1. Demographic data of pediatric patients in 2,192 parenteral nutrition orders

\begin{tabular}{lc}
\hline Characteristics & Number of orders (\%) \\
\hline Sex & $1,154(52.6)$ \\
Male & $1,038(47.4)$ \\
Female & \\
Age & $1,859(84.8)$ \\
Newborn to 12 months & $333(15.2)$ \\
$>12$ months & \\
Primary medical conditions & $220(10.0)$ \\
Short bowel syndrome & $837(38.2)$ \\
Preterm or very low-birth-weight infant & $1,096(50.0)$ \\
Others* & $39(1.8)$ \\
Not specified & $6(0.3)$ \\
Nutritional assessment according to pediatricians & \\
Normal & $1,212(55.3)$ \\
Mild malnutrition & $518(23.6)$ \\
Moderate malnutrition & $209(9.5)$ \\
Severe malnutrition & $247(11.3)$ \\
Not specified &
\end{tabular}

*Necrotizing enterocolitis, encephalitis, gastroschisis, omphalocele, inflammatory bowel disease, sepsis, chylothorax, gut perforation, gut obstruction, and congenital heart defect, etc.
The reviewed pediatric parenteral nutrition orders were analyzed separately according to the route of administration (Table 2). Kolmogorov-Smirnov test results were significant; therefore, nonparametric statistics were used and all data are shown as median and ranges of 25 th percentile to 75 th percentile. Overall, 1,347 pediatric parenteral nutrition orders were administered through a central line $(61.5 \%)$ and 845 orders were administered through a peripheral line (38.5\%).

In central parenteral nutrition orders, median phosphorus concentrations between the 3 groups were not significantly different $(P=0.11)$, while calcium concentrations were significantly higher in the parenteral nutrition solutions containing NaGlyP than in those containing dipotassium phosphates or mixed phosphate salts $(P<0.001)$. Bags with pediatric parenteral nutrition containing NaGlyP had higher sodium concentrations than those containing dipotassium phosphate $(P<0.001)$ as a result of the sodium content of NaGlyP and other sodium sources such as sodium chloride and sodium acetate. One order $(0.1 \%)$ containing NaGlyP required calcium concentration reduction from 10.09 to $4.13 \mathrm{mmol} / \mathrm{L}$. By contrast, almost half $(44.2 \%)$ of the solutions containing dipotassium phosphates required calcium concentration reductions from 1.10 130.34 to $0.50-10.27 \mathrm{mmol} / \mathrm{L}$ with the range of reduction at $0.43-122.20 \mathrm{mmol} / \mathrm{L}$. Concentrations of amino acids in parenteral nutrition solutions with mixed both phosphate salts were lower than those in the parenteral nutrition bags containing either NaGlyP $(P=0.02)$ or dipotassium phosphate $(P=0.02)$ alone. Although trace element content was significantly different between the 3 groups, zinc, copper, manganese, selenium, fluoride, and iodine (from Peditrace) were only added in very small concentrations and would most likely not have had significant influence on the risk of calcium-phosphate precipitation.

In parenteral nutrition orders administered peripherally, median calcium and phosphorus concentrations were significantly higher in the parenteral nutrition solutions containing NaGlyP than they were in bags containing dipotassium phosphates $(P<0.001)$ or mixed phosphate salts $(P=0.03)$. Two orders $(67 \%)$ containing dipotassium phosphate required calcium concentration reductions from 3.66-4.29 to $1.95-3.33 \mathrm{mmol} / \mathrm{L}$ with the range of reduction at $0.33-$ $2.34 \mathrm{mmol} / \mathrm{L}$. By contrast, no calcium concentration reduction was needed in peripheral parenteral nutrition containing either NaGlyP or mixed phosphate salts.

Subgroup analysis of mineral and amino acid concentrations in parenteral nutrition solutions was further performed in preterm infants (Table 3). Only NaGlyP was used in both central and peripheral lines. The results showed high parenteral calcium and phosphorus prescription in preterm infants. Interestingly, in parenteral nutrition orders for preterm infants to be administered centrally, median calcium and phosphorus concentrations were 


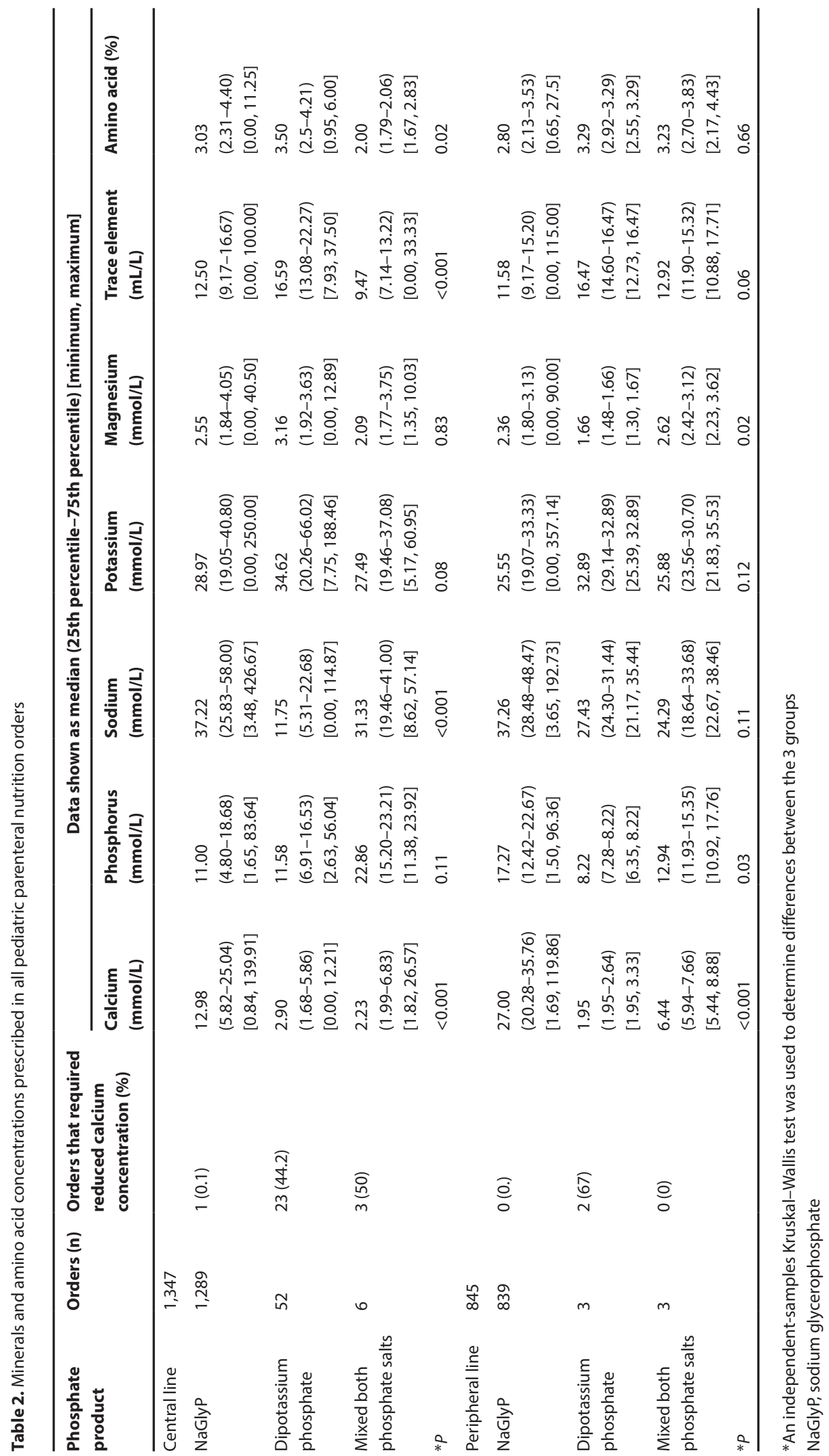


Table 3. Mineral and amino acid concentrations prescribed in preterm infants

\begin{tabular}{|c|c|c|c|c|c|c|c|}
\hline \multirow{2}{*}{$\begin{array}{l}\text { Phosphate products } \\
\text { (No. orders) }\end{array}$} & \multicolumn{7}{|c|}{ Data shown as median (25th percentile-75th percentile) [minimum, maximum] } \\
\hline & $\begin{array}{l}\text { Calcium } \\
\text { (mmol/L) }\end{array}$ & $\begin{array}{l}\text { Phosphorus } \\
\text { (mmol/L) }\end{array}$ & $\begin{array}{l}\text { Sodium } \\
\text { (mmol/L) }\end{array}$ & $\begin{array}{l}\text { Potassium } \\
\text { (mmol/L) }\end{array}$ & $\begin{array}{l}\text { Magnesium } \\
\text { (mmol/L) }\end{array}$ & $\begin{array}{c}\text { Trace element } \\
(\mathrm{mL} / \mathrm{L})\end{array}$ & Amino acid (\%) \\
\hline \multicolumn{8}{|l|}{ NaGlyP } \\
\hline $\begin{array}{l}\text { Central line } \\
(227)\end{array}$ & $\begin{array}{c}29.36 \\
(22.27-37.99) \\
{[2.37,83.25]}\end{array}$ & $\begin{array}{c}17.00 \\
(12.07-23.50) \\
{[1.74,50.00]}\end{array}$ & $\begin{array}{c}35.56 \\
(26.67-50.91) \\
{[3.48,118.81]}\end{array}$ & $\begin{array}{c}25.45 \\
(18.18-33.33) \\
{[0.00,112.06]}\end{array}$ & $\begin{array}{c}2.58 \\
(1.84-3.24) \\
{[0.00,9.64]}\end{array}$ & $\begin{array}{c}12.50 \\
(9.11-15.58) \\
{[6.25,37.50]}\end{array}$ & $\begin{array}{c}2.72 \\
(2.00-3.83) \\
{[0.63,11.25]}\end{array}$ \\
\hline $\begin{array}{l}\text { Peripheral line } \\
(362)\end{array}$ & $\begin{array}{c}30.00 \\
(24.19-39.63) \\
{[3.60,75.09]}\end{array}$ & $\begin{array}{c}18.93 \\
(14.01-25.00) \\
{[2.82,50.00]}\end{array}$ & $\begin{array}{c}38.75 \\
(29.20-48.47) \\
{[11.82,100.00]}\end{array}$ & $\begin{array}{c}26.20 \\
(20.00-34.00) \\
{[0.00,65.00]}\end{array}$ & $\begin{array}{c}2.48 \\
(1.97-3.32) \\
{[0.00,40.5]}\end{array}$ & $\begin{array}{c}12.29 \\
(9.85-16.52) \\
{[6.36,115.00]}\end{array}$ & $\begin{array}{c}3.00 \\
(2.33-3.69) \\
{[0.70,8.25]}\end{array}$ \\
\hline
\end{tabular}

NaGlyP, sodium glycerophosphate

Table 4. Costs of phosphate products used per bag

\begin{tabular}{lcc}
\hline $\begin{array}{l}\text { Phosphate } \\
\text { products }\end{array}$ & $\begin{array}{c}\text { Costs (USD)/bag } \\
\text { median } \\
\text { (25th percentile-75th } \\
\text { percentile) }\end{array}$ & $\begin{array}{c}\text { Costs (THB)/bag } \\
\text { median } \\
\text { [minimum, maximum] }\end{array}$ \\
$\begin{array}{lcc}\text { (25th percentile-75th } \\
\text { percentile) }\end{array}$ \\
\hline NaGly & 1.04 & 35.88 \\
& $(0.77-1.45)$ & $(26.22-49.68)$ \\
Dipotassium & {$[0.16,32.77]$} & {$[5.52,1,121.94]$} \\
phosphate & 1.20 & 41.25 \\
& $(0.56-1.57)$ & $(19.35-53.66)$ \\
Mixed both & {$[0.26,14.34]$} & {$[9.13,490.93]$} \\
phosphate salts & 2.03 & 69.63 \\
& $(1.58-2.11)$ & $(53.97-72.22)$ \\
$P^{*}$ & {$[0.59,5.48]$} & {$[20.25,187.96]$} \\
\hline
\end{tabular}

${ }^{*}$ An independent-samples Kruskal-Wallis test was used to determine differences between the 3 groups

NaGlyP, sodium glycerophosphate; THB, Thai baht

obviously higher than those in orders for all cases $(P<0.001)$. The median calcium and phosphorus concentrations in parenteral nutrition orders for preterm infants to be administered peripherally were slightly higher than those in orders for all cases. The other components were not significantly different.

According to the prices of NaGlyP and dipotassium phosphate provided at the Department of Pharmacy, King Chulalongkorn Memorial Hospital, $1 \mathrm{mmol}$ of phosphate as NaGlyP cost 0.40 USD (13.80 Thai baht [THB]) and $1 \mathrm{mmol}$ of phosphate as dipotassium phosphate cost 0.21 USD (7.30 THB; 1 USD equivalent to 34.241 THB, U.S. Federal Reserve Bank G5.A annual average rate 2015). Median costs of phosphate used per parenteral nutrition bag were higher for mixed phosphate salts than for either NaGlyP or dipotassium phosphate alone ( $P=0.03$ and $P=0.04$, respectively; Table 4). However, a parenteral nutrition bag containing NaGlyP had a high cost for phosphate of up to 32.77 USD (1,122 THB). A parenteral nutrition bag containing dipotassium phosphate had relatively low cost (up to 14.34 USD or 491 THB).

\section{Discussion}

In the present study, we reviewed 2,192 parenteral nutrition orders made over 1 year. A maximum calcium gluconate concentration at $139.91 \mathrm{mmol} / \mathrm{L}$ was mixed with NaGlyP $83.64 \mathrm{mmol} / \mathrm{L}$ and $5.6 \%$ amino acid in $55 \mathrm{~mL}$ of central parenteral nutrition solution. By contrast, a maximum calcium gluconate concentration at $12.21 \mathrm{mmol} / \mathrm{L}$ was mixed with dipotassium phosphate $3.87 \mathrm{mmol} / \mathrm{L}$ and $3.1 \%$ amino acids in $400 \mathrm{~mL}$ of central parenteral nutrition solution. There was no record of any visible particle appearing in a bag containing the parenteral solution either when mixing or at any time during administration. Calcium concentrations mixed with NaGlyP in pediatric parenteral nutrition solutions reported in the present study were considerably higher than those reported in published studies of intravenous calcium and phosphate stability $[6,9,10]$. The use of NaGlyP allowed greater concentrations that were compatible with calcium, which may be necessary for preterm infants who require high amounts of calcium and phosphate [1]. Other organic salts of phosphate such as sodium glucose-1-phosphate, sodium D-fructose-1,6-diphosphate, and fructose-1,6-bisphosphate are also properly compatible with calcium, even under conditions that produce a high risk of precipitation $[8,16,17]$. Due to the relatively low dissociation characteristics of phosphate from the organic salts, the risk of calcium-phosphate precipitation may be considered lower than that produced by inorganic salts. The absence of precipitation enables parenteral nutrition formulations, reduces the admixture wastage, and avoids clinical complications $[1,4]$.

The present study also investigated the costs of different phosphate salts used in pediatric parenteral nutrition solutions. 
At King Chulalongkorn Memorial Hospital pharmacy, $1 \mathrm{~mL}$ of NaGlyP solution costs 0.40 USD and contains $1 \mathrm{mmol}$ of phosphate and $2 \mathrm{mmol}$ of sodium. One milliliter of dipotassium phosphate costs 0.11 USD and contains $0.5 \mathrm{mmol}$ of phosphate and $1 \mathrm{mmol}$ of potassium. Considering the similar amount of phosphorus in the product, NaGlyP is approximately 2 times more expensive than dipotassium phosphate in our pharmacy. The price differential is less than the 5-10 times mentioned by Pereira-da-Silva et al. [3]. Even though the present study did not find a significant difference between the costs of NaGlyP and dipotassium phosphate used in pediatric parenteral nutrition solutions, NaGlyP should only be prescribed for patients who require high amounts of calcium and phosphorus or with suspected high risk of hazards related to calcium-phosphate precipitates. The responses of patients to the parenteral nutrition solutions containing organic phosphate should be carefully monitored, and blood chemistry should be measured to avoid any clinical complications. For example, especially in patients with kidney insufficiency, the aggressive replacement of phosphate may disturb the phosphate homeostasis resulting in clinical symptoms such as changes in mental state, vascular calcification, ventricular dysfunction, and premature death [18]. Apart from the cost, organic phosphate products are sometimes unavailable or not universally approved [12, 14]; therefore, dipotassium phosphate remains the main source of intravenous phosphate supply in many settings.

Limitations of this study include its retrospective design; therefore, the reason for calcium concentration reduction in the parenteral nutrition orders was unclear. The concentration changes may have been a response to changes in the conditions of patients, other than the risk of calcium-phosphate precipitation. Moreover, our data represented only the findings from a single hospital, and the cost analysis was based on local hospital billing rates, without considering other indirect costs. It may not be possible to generalize the results to populations in other hospitals or in other health care systems. The calcium and phosphate compatibility in parenteral solutions in the hospital has only relied on precipitates detected macroscopically; however, microprecipitates may occur without precipitates detected macroscopically $[13,19]$. Some particles from microprecipitation have a diameter larger than a human capillary [13]; therefore, risks from microprecipitation cannot be excluded; and caution must be applied when using the mineral concentrations reported from this study.

\section{Conclusions}

The calcium concentrations in the mixtures with NaGlyP were higher than the calcium concentrations mixed with dipotassium phosphate. Despite the higher cost, NaGlyP is a useful source of phosphate for pediatric patients who need high amounts of calcium in parenteral nutrition. Further studies of the compatibility of calcium and NaGlyP in pediatric parenteral nutrition solutions in various storage conditions and the clinical outcomes of patients using these solutions are warranted.

Author contributions. Both the authors made substantial contributions to the conception and design of the study and acquisition of the data. TS substantially analyzed and interpreted the data. Both authors drafted the manuscript, and TS critically revised it. Both authors approved the final version of the manuscript submitted for publication and take responsibility for the statements made in the published article.

Acknowledgments. We thank Miss Piyapat Ongartittichai, Miss Hathaichanok Teeratadakul, and Mr. Abdulhakim Chitmittrapab for their help in collecting data. The authors were supported by a grant from the Ratchadaphiseksomphot Endowment Fund from Chulalongkorn University.

Conflict of interest statement. The authors have each completed and submitted an International Committee of Medical Journal Editors Uniform Disclosure Form for Potential Conflicts of Interest. None of the authors have any potential conflict of interest to disclose.

\section{References}

[1] Mihatsch W, Fewtrell M, Goulet O, Molgaard C, Picaud JC, Senterre T; ESPGHAN/ESPEN/ESPR/CSPEN working group on pediatric parenteral nutrition. ESPGHAN/ESPEN/ESPR/CSPEN guidelines on pediatric parenteral nutrition: Calcium, phosphorus and magnesium. Clin Nutr. 2018; 37:2360-5.

[2] Pereira-da-Silva L, Costa AB, Pereira L, Filipe AF, Virella D, Leal E, et al. Early high calcium and phosphorus intake by parenteral nutrition prevents short-term bone strength decline in preterm infants. J Pediatr Gastroenterol Nutr. 2011; 52:203-9.

[3] Pereira-da-Silva L, Macedoc I, Rosa ML, Bridgese KM. Calcium and phosphorus intake by parenteral nutrition in preterm infants. In: Rajendram R, Preedy VR, Patel VB, editors. Diet and nutrition in critical care. New York: Springer; 2015, p. 1-16.

[4] Newton DW, Driscoll DF. Calcium and phosphate compatibility: revisited again. Am J Health Syst Pharm. 2008; 65:73-80.

[5] Kimura S, Nose O, Seino Y, Harada T, Kanaya S, Yabuuchi H, et al. Effects of alternate and simultaneous administrations of calcium and phosphorus on calcium metabolism in children receiving total parenteral nutrition. J Parenter Enteral Nutr. 1986; 10:513-6.

[6] MacKay M, Anderson C. Physical compatibility of sodium glycerophosphate and calcium gluconate in pediatric parenteral nutrition solutions. JPEN J Parenter Enteral Nutr. 2015; 39:725-8. 
[7] Mirtallo J, Canada T, Johnson D, Kumpf V, Petersen C, Sacks G; Task Force for the Revision of Safe Practices for Parenteral Nutrition. Safe practices for parenteral nutrition. J Parenter Enteral Nutr. 2004; 28:S39-70.

[8] Bouchoud L, Fonzo-Christe C, Sadeghipour F, Bonnabry P. Maximizing calcium and phosphate content in neonatal parenteral nutrition solutions using organic calcium and phosphate salts. J Parenter Enteral Nutr. 2010; 34:542-5.

[9] Anderson C, MacKay M. Physical compatibility of calcium chloride and sodium glycerophosphate in pediatric parenteral nutrition solutions. J Parenter Enteral Nutr. 2016; 40:1166-9.

[10] Thowladda N, Siritientong T. Compatibility of calcium and sodium glycerophosphate in parenteral nutrition solutions. Thai J Pharm Sci. 2016; 40(Suppl):176-9.

[11] Ronchera-Oms CL, Jiménez NV, Peidro J. Stability of parenteral nutrition admixtures containing organic phosphate. Clin Nutr. 1995; 14:373-80.

[12] de Oliveira Ribeiro D, Lobo BW, Volpato NM, da Veiga VF, Cabral LM, de Sousa VP. Influence of the calcium concentration in the presence of organic phosphorus on the physicochemical compatibility and stability of all-in-one admixtures for neonatal use. Nutr J. 2009; 8:51.

[13] Thowladda N, Siritientong T. Are there maximum compatible concentrations of calcium gluconate and sodium glycerophosphate in infant parenteral nutrition solutions? J Pharm Sci Res. 2018; 10:2074-8.

[14] Hicks W, Hardy G. Phosphate supplementation for hypophosphatemia and parenteral nutrition. Curr Opin Clin Nutr Metab Care. 2001; 4:227-33.

[15] Pereira-da-Silva L, Nurmamodo A, Amaral JM, Rosa ML, Almeida MC, Ribeiro ML. Compatibility of calcium and phosphate in four parenteral nutrition solutions for preterm neonates. Am J Health Syst Pharm. 2003; 60:1041-4.

[16] Prinzivalli M, Ceccarelli S. Sodium d-fructose-1,6-diphosphate $v$. sodium monohydrogen phosphate in total parenteral nutrition: a comparative in vitro assessment of calcium/phosphate compatibility. J Parenter Enteral Nutr. 1999; 23:326-32.

[17] Zenoni D, Loiacono S. Experience of compounding total parenteral nutrition admixtures for preterm infants in a hospital pharmacy: evidence of calcium and phosphate compatibility problem. Eur J Hosp Pharm. 2018; 25:38-42.

[18] Vervloet MG, van Ballegooijen AJ. Prevention and treatment of hyperphosphatemia in chronic kidney disease. Kidney Int. 2018; 93:1060-72.

[19] Joy J, Silvestri AP, Franke R, Bistrian BR, Nehne J, Newton DW, Driscoll DF. Calcium and phosphate compatibility in low-osmolarity parenteral nutrition admixtures intended for peripheral vein administration. J Parenter Enteral Nutr. 2010; 34:46-54. 